\title{
Remote Automated Controlled Irrigation Systems and the Principles of Their Functioning in the Conditions of Azerbaijan
}

\author{
RANS Aliev ZH* \\ Institute of Soil Science and Agrochemistry of NAS of Azerbaijan, Azerbaijan
}

Received: 阱 August 05, 2018; Published: 制 August 14, 2018

*Corresponding author: RANS Aliev ZH, Institute of Soil Science and Agrochemistry of NAS of Azerbaijan, Azerbaija

\begin{abstract}
This article examines the current state of soil and water resources, farmland t.ch.i Azerbaijan Republic, the problem of progressive water and wind soil degradation , the need for the organization of agriculture , taking into account the introduction of automated control systems for irrigation using water saving technology and hardware equipment in it, the study of the characteristics and analysis of experience implementing measures to stabilize ecological and drainage system of agriculture in conditions of insufficient moisture areas in the country, as well as basic aspects of development of environmental reclamation approach balanced, rational use of a particular system of crop rotation and crop taking into account the requirements of economic development and environmental management.
\end{abstract}

Keywords: Irrigation; Technology; Degradation; Automated Management of Low-Intensity Zones; Agriculture

\section{Introduction}

Figure 1 The main directions of the economic and social development of the republic are the intensification of agricultural production. Irrigation is a powerful means of intensifying agricultural production in the conditions of its specialization. In areas of insufficient moisture (especially characteristic of mountainous areas), irrigation is one of the decisive factors in the cultivation of high and stable crop yields. Purpose of the research: To this end, it is necessary to develop new technical solutions and introduce automated low-intensity irrigation systems for agricultural crops that meet the requirements of the environment and protect their habitat, which allows improving the ecological status of irrigated land, reducing water consumption per unit and increasing yields crops on the irrigated field.

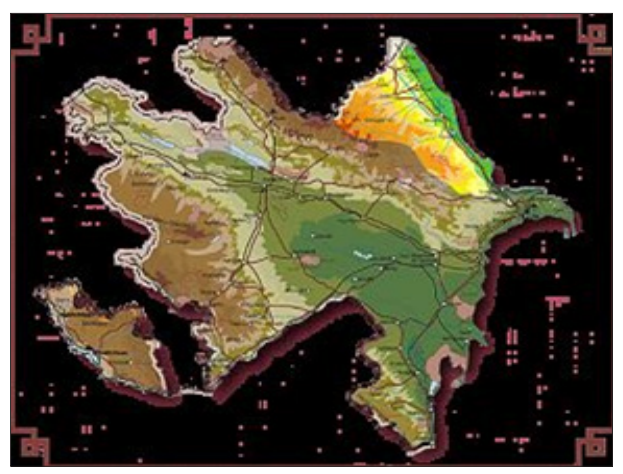

Figure 1.

\section{Methods of Research and Discussion}

Irrigated soils in Azerbaijan cover 1,45 thousand hectares. It is believed that the use of automation also applies to factors directly affecting the entrainment of crop yields and increasing the productivity of each hectare of arable land and agricultural land with minimal outlays of labor and resources. Automated irrigation increases the efficiency of all the intensification factors: chemicalization, complex mechanization, renewal grade, intensive technology, etc. It allows creating large zones of guaranteed crop production [1-3]. 


\section{Objects of Research}

The object of the study is to study and create methods of correct regulation of water consumption and plant nutrition by irrigation, depending on the weather conditions. To this end, we have developed and implemented in the design of systems for automated control of low-intensity irrigation systems based on a self-oscillating micro-oxidizer successfully passed the resource test, tested on selected soils under the orchard, in the Guba-Khachmas zone on the Shahdag foothills located above the sea level at 600 meters with a slope of the terrain of 0.02 . (See Principal scheme of a pulse sprinkler system of self-oscillating action with automated control Figure 2) [4-8].

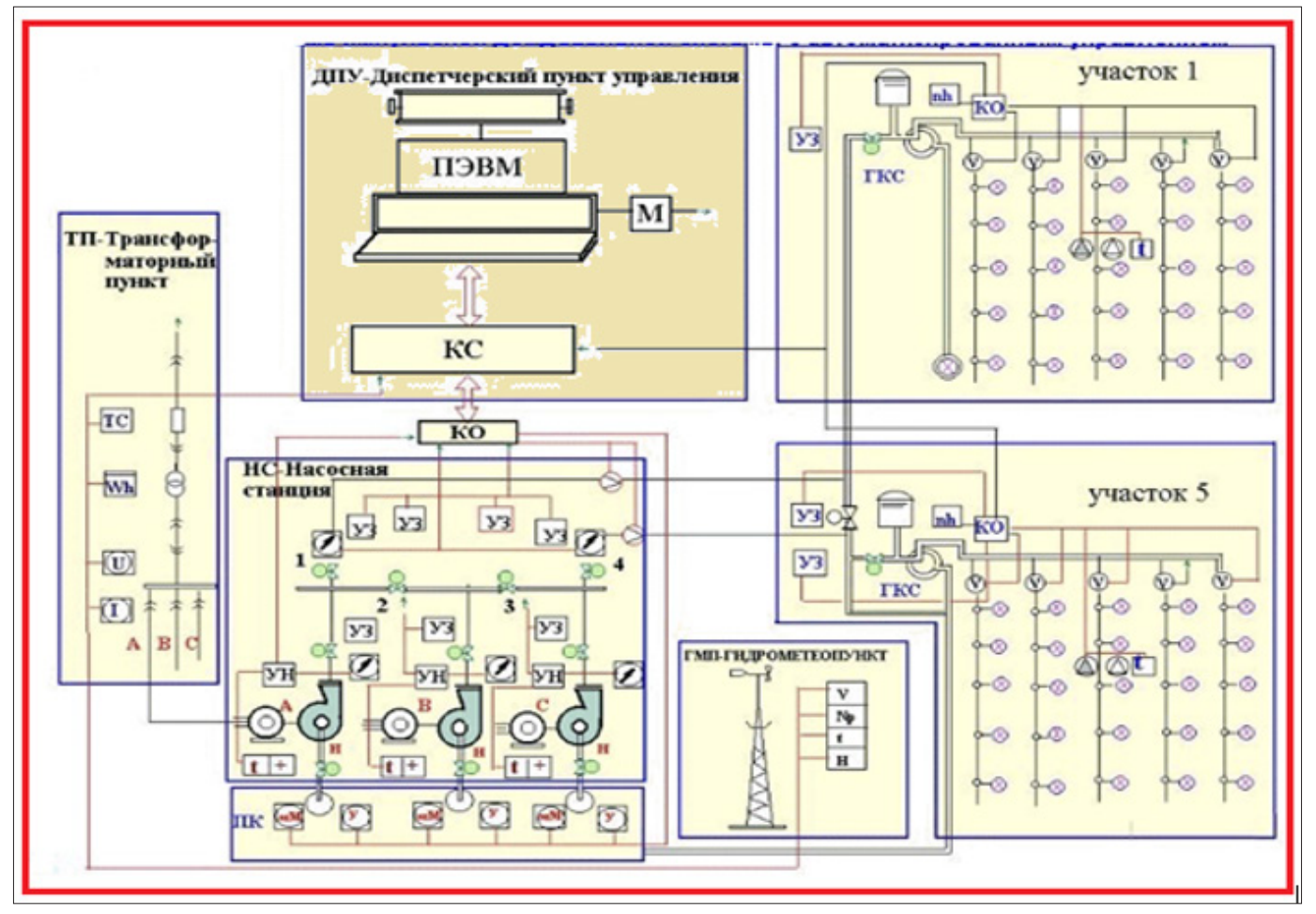

Figure 2: Schematic diagram of a pulse sprinkler system of self-oscillating action with automated control.

\section{Constructions and Functional Descriptions of the SMO $\mathrm{AU}$}

So, for the operational control of weather conditions in the region, which are necessary for solving the planning and operational management of irrigation of crop fields, metering sensors with transducers for telemetric counting of the main parameters are installed at the local hydro meteorological point:

a) Wind speed $-V$ analog signal (TIT) with a period of recording the parameter values in a cycle of 30 minutes.

b) Air temperature -tv, analogue signal (TIT) with a period of recording the parameter values in a cycle of $30 \mathrm{~min}$.

c) Air humidity -Wв, analogue signal (ТИТ) with a period of recording the parameter values in a cycle of $30 \mathrm{~min}$.

The values of the parameters in the telemetry code are calculated by the intelligent object controller (KO) installed in the transformer station through the radio channel communicating with the transducer sensors.

In the CC, the measured telemetry codes are processed by the primary processing, averaging and stored in the RAM, which are stored before they are counted by the communication controller (CS) installed in the operational control room of the technological process (ASMO) -operator. To monitor and manage the power supply to ASMO facilities and to account for electricity consumption at the transformer station (TP) (see the structural and principle diagram of the APCS of irrigation), transducer sensors are installed:

a) measuring the voltage at the input in the TP-U (analog signal (TIT);

b) load measurement of consumers -I U (analog signal (TIT);

c) Accounting for electricity consumption -Wh (discrete integrated signal-TII;

d) control of the position of the switches (switching-off of electrical consumers) -SC (discrete signal TCC position).

The report of the parameter values in the telemetry code is carried out by the intelligent object controller (CO) over the local wire communication channels and, after their initial processing and averaging, are recorded in the operative memory. For monitoring and control of the technological process of the water intake, sludge (treatment facilities) and pumping station water in pipelines) are 
installed sensors-converters specified in the structural-functional scheme:

a) turbidity of water in sedimentation tanks-M (analog si nal TIT readable in a cycle of $30 \mathrm{~min}$ );

b) the water level in the sedimentation chambers-H (analog signal TIT, read in the cycle $30 \mathrm{~min}$ );

c) water pressure -P, installed on pumps, collection and distribution manifolds (analogue signal TIT, read in a cycle of 30 minutes);

d) measurement of load of electric motors -I (analogue signal TIT, read in cycle $30 \mathrm{~min}$ );

e) positions of the gate valves-PZ (discrete TCC signal, read in cycle $1 \mathrm{~s})$;

f) the positions of the power switches

(Discrete signal TCC, read in cycle 1s) g) alarm-AS (discrete signal TCA, read in cycle $1 \mathrm{~s}$, priority), h) measurement of water flow, supplied by pumps and in the distribution pipeline -Q (integrated signal TII, processed in a cycle of 1 hour).

Monitoring of soil condition and management of the irrigation technological process is carried out according to individual irrigation fields on the basis of measurements of agrophysical and technological parameters by transducer sensors:

a) soil moisture VLP- (analogue signal TIT with recording in a cycle of $30 \mathrm{~min}$ ) b) evaporation of water from the soil surface Isp - (analogue signal TIT with recording in the cycle of $30 \mathrm{~min}$ ) c) soil temperature $-t^{\circ}$ - (analogue signal TIT with recording in the cycle of $30 \mathrm{~min}$ ) d) water flow rate for irrigation through the distribution pipeline of the section -Q - (integrated beep recording in a cycle of 30 minutes) e) switching on the GCS -discrete signal readable in a cycle of $30 \mathrm{~s}$, e) the position of the switching gate- (discrete position signal TCC-reading cycle 30 s).

b) The signal in the telemetry code is transmitted by the intelligent object field controller via radio channels and after their initial processing and averaging by the processor are written into RAM

Entering operational data into the computer and forming a database (OBD) The data recorded in the operative memory of the object controllers (KO) is counted by the program $\mathrm{m}$ but the radio channels and wired communication connection controller (CC) connected to a computer control station (AP) (see. a schematic diagram of a low-intensity irrigation system with automated control), according to a specified schedule, and written to its operational memory in the structure of the telemetry file (see Information Support). The computer uses the exchange programs to count the data from the RAM of the coprocessor, recodes them and writes them to the operational database, from which it displays them in real time to display on the mimics, and after linearization and averaging, the data for their program codes are written to the storage bases, the cat structures They are listed in the information support, and this forms the Bank of Data of the ASMO task complex. [1.3,].

Information flows of the automated low-intensity irrigation system (ASMO). Before recording to the Data Bank, the flow of measurement data is analyzed according to predetermined algorithms and, when analyzing results having deviations from the settings specified in the regulations, is recorded in the operational control database (OBU) by the technological process. The operational base of program management, but according to the cycle specified in the regulations, is counted by the control module in the technological directions and in the presence of deviations in the data records forms direction of the control signal to the required executive body. Organization of data collection and transmission via Internet.3.1. Terms of data exchange: 3.1.1. Data exchange on the operation of the irrigation system is carried out through the World Wide Web. For this, it is necessary to connect the modem through a computer to the telephone network and obtain the right to access the Internet from the provider. This condition extends to each subscriber. If these conditions are met, the "Center's computer can connect to computers in the irrigation areas of the regions of Azerbaijan and other countries." 3.1.2. The site of the irrigation system is being organized, visitors of which will see: the latest data on the state of the system, interactive pages created using PHP technology, and the real-time exchange of data and messages. 3.1.3. With the help of Skype 3, users can talk over the phone and when using cameras to see each other, and with streaming video programs to review the state of the site. When instrumental parameter measurements, it is necessary to take into account the available scatter of the measured values. The number of readings repeated by the formula determines the value of the parameter, which can be taken as the actual value with a probability of 0.8 :

$\left.n_{-} 0.8 E x=1.64 * 0.001\left(S I G_{-} B\right) *((W(H B) / 10 * h) * * 2)\right)+2,27,(1)$

where: $\mathrm{n}=0,8$ (TP) - the number of repetitions of measurements corresponding to the probability of $0.8, \mathrm{~m}-0.8$ (TP) -accuracy of measurements (mm) sb-standard Measurement error, \% b (HB) $\mathrm{W}$ (HB) -Passage moisture, mm for humidity b (HB) in the control layer h (a), m.4. Measurement of initial (starting) soil moisture and calculation of initial moisture reserves W0 in soil4.1.

\section{General Description of the Problem}

The initial moisture reserves of $\mathrm{W} 0$ in the active soil layer are determined by the formula:

$$
d W H B=W(\text { tau })-W(H B),(2)
$$

where: $\mathrm{h}$ (a) -active soil layer, $\mathrm{m}$ (it is assumed that the active soil layer is divided into layers 0,20-0,30 m) $\gamma$-average for the layer soil density, $\mathrm{t} / \mathrm{m}^{3}$ record in the code of the program-gamma_srbt -soilness of the soil in the field section in \% to the mass dry record in the code of the soil program at the considered moment - (Veta_ tau). With the automated determination of the initial moisture reserves in the soil, it is assumed that the value of $\beta \tau$ (Вета_tau) is determined by the humidity meter installed in the balance area of the field according to n0.8 (TP) measurements (entry in program code $n_{-} 0.8$ Ex). Measured the parameter values are automatically 
written to the DataPar.dbf Data Bank file by the N_code of the element to which the parameter belongs (see the special section "Information Support"). [3.4.]. To specify the calculation conditions, the values of the required conditionally variable variables are recorded in the task for solving the problems (see ZADANIE_3 in the information support). By determining the value of the initial (initial) soil moisture, the moisture reserve deficit and the necessary irrigation rates are programmatically determined. The results of the task solution are recorded in the output document DOC_3 and are displayed as a chart.4.2. Description of the algorithm in accordance with the task of determining the soil moisture and moisture reserves in the field of irrigation (see the information section "REST_3) .4.2.1 Finding values from the database (from the Information Support section): - the parameter values are automatically read from the DataPar file .dbf on the N_code of the element to which the parameter belongs;

-The value of the N_code of the element is read from the ELEM file. dbf at the key:

$S L_{-} S Y S T+S S Y S T+S L_{-} M O D Y L E+S L_{-} G R O U P+S L_{-} V I D+S L_{-} T Y P E .(3)$

Form the key for searching N_code (see statement to the operator):

a. From the SL_SYST.dbf file, select the system to which the element parameter belongs.

b. From the SL_SSYST.dbf file select the subsystem from the file + SL_MODYLE .dbf-module.

c. From the file SL_GROUP.dbf -group to which the element of the measured parameter belongs.d) From the file SL_VID.dbf -the item of the measured parameter.

d. From the file SL_ TYPE .dbf is the type of the element of the measured parameter. j) NAME-the element name is entered from the keyboard;

If the elements defined by the coupler are somewhat (see ZADANIE_3, record 4), then the number of the element is added to the name via the separator [_] - (NAME_1>) /. On the generated link is TLS_X.dbfN_code.

From the DataPar.dbf by N_code + Zdate and the name of the parameter $<$ PARAM $>$ marked in ZADANIE_3 $(+)$ is programmed with its ZNACH value for each field. 4.2.2. The found values of the parameters-the humidity for a given date BETA_tau or the moisture reserves for a given date $\mathrm{W}$ (tau) for each section of the field are recorded in the output document DOC.3, see the layout of the output documents "Burst of moisture over irrigation fields". After determining the moisture content of BETA_tau or the moisture reserve in the soil $\mathrm{W}$ (tau), a moisture deficit or a moisture reserve in the soil is determined. [2.8,] 4.2.3. Determination of moisture deficit and moisture reserves in the soil in the field area. A) If ZADANIE_3 is determined by the moisture content of BETA_tau and its value is found from DataPar.dbf, the moisture deficit relative to the moisture of the least water consumption BETA_ (HB) is: $[2,4,6,8]$

dBETA_HB = BETA_(HB) -BETA_tau (3) where, BETA_(HB) is from SF_Plot.dbf and ConSoil.dbf; BETA_tau -from 4.2.3. The obtained values of humidity deficit are automatically recorded in the output document DOC.3b) If ZADANIE_3 determines the moisture reserve in the soil $\mathrm{W}$ (tau) and its value is found from DataPar.dbf, then moisture moisture deficit at the lowest moisture capacity

$$
d W(H B) i s: d W(H B)=W(\text { tau })-W(H B)(4)
$$

where, W (HB) is from SF_Plot.dbf and ConSoil.dbf; W_tau -from 4.2.34.2.4 After determining the data for each of the specified sections of the field, a) the average moisture content of BETA_AV and the moisture content in the W_AV soil as a whole over the field is determined:

$$
\text { BETA_AV }=1 / n \sum\left(B E T A_{-} \text {tau }\right)
$$

Where, $\mathrm{n}$ is the number of balanced sections participating in the calculation, from ZADANIE_3, record 4; (BETA_tau) i is the moisture content of the soil relative to the dry soil from 4.2 .1 for each plot. B) If (W_tau) was determined, then the average moisture reserve in the soil of the whole field is

$$
\text { dBETA_AV }=1 / n * \Sigma\left(d B E T A_{-} \text {tau }\right) I(6)
$$

e. the average value of the deficit of the moisture reserve in the soil of the field:

$$
d W_{-} A V=1 / n \Sigma\left(d W_{-} A W\right) I
$$

The calculated values in 4.2.3a), b), c), d) are automatically written in the line < field ....... > e) The values of the parameters determined in columns 4.5 and 6 DOC. 3 are displayed with a bar graph "Moisture drop over the irrigation field".

f. After viewing the DOC.3 document, you will be prompted to $<$ Will solve the task for other farm fields on this date $>$. $\langle$ Yes $>$, $<$ No $>$. When you enter $<$ Yes $>$, the message $<$ Enter the field and farm name in ZADANIE_3 $>$ is displayed and displayed on the ZADANIE screen for data entry.4.2.4 If the value of the parameters specified in ZADANIE_3 is not present in the database, then the message $<$ Value of the parameters specified in ZADANIE in the database are absent. Will you measure these parameters? $<$ Yes $>$, $<\mathrm{No}>$. If $<$ Yes $>$, then go to Section 4.2.1.

If $<\mathrm{No}>$, then the solution of the problem is completed and exit to the MENU.4.2.5 Before the measurement starts, the number of measurements in each section is determined that ensures the probability of the received value is not less than 0.8 with the minimum labor costs for the measurement $\left.\left.n_{-} 0.8 E x: n_{-} 0.8 E x:=1,64 * 0.001\left(S I G_{-} B\right) *(W(H B) / 10 * h)^{* * 2}\right)\right)+2.27(8)$

where: SIG_B is the specified standard error in\%; BETA (HB) -from ZADANIE_3; -W (HB) - moisture vapor in the soil, in mm with BETA (HB) moisture content of SF_Plot.dbf; -h-depth of soil layer $(\mathrm{mm})$ in which the measurement is to be carried out. 4.2. 6 Run $\mathrm{n} \_0.8$ Ex measurements on the specified parameter ZADANIE_3, line 2 on each section and write the data in DataPar.dbf to N_code, Zdate, Ztime.4.2.7. Calculate the average of the measurements made (take a sample from DataPar.dbf by N_code + Zdate. The average moisture reserve in the W_AV soil is:

$$
W_{-} A V=1 / n_{-} 0.8 E x * \Sigma\left(W_{-} 0.8 E x\right) i(\mathrm{~mm})(9)
$$


where,

W_0, 8Ex is the moisture reserve value for each measurement selected in $\S 4.2 .6$ (If the soil moisture content was measured BETA_0.8Ex, then the average moisture value

$$
B E T A_{-} A V: B E T A_{-} A V=1 / n_{-} 0.8 E x * \Sigma\left(B E T A_{-} 0.8 E x\right) i(\%)(10)
$$

Where,

BETA_0,8 Ex-value of soil moisture for each measurement, calculate the calculated values:

i. $\quad$ W_AV: $=\mathrm{W}(\mathrm{tau})$;

ii. BETA_AV: = BETA_tau and write to the output document DOC.3 as in 4.2.1 and further as 4.2.2; 4.2.3.4.2.8 The completed document DOC.3 is recorded in the folder for sending via the Internet. The codes of the programs are given in a separate appendix.

\section{Conclusion}

The results of the research reveal the possibilities for an operative solution of the complex problems of the operational determination of agro-meliorative parameters.

\section{ISSN: 2574-1241}

DOI: 10.26717/BJSTR.2018.08.001586

RANS Aliev ZH. Biomed J Sci \& Tech Res

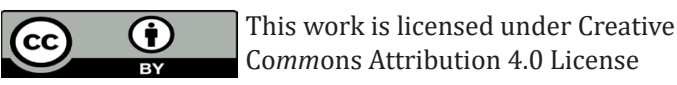

Submission Link: https://biomedres.us/submit-manuscript.php

\section{References}

1. BH Aliev, Aliev ZH (2001) Zoning of territory of the Republic of Azerbaijan on selected advanced irrigation techniques. /Monograph, Publishing house "Ziya”. Baku pp. 297.

2. BH Aliev, Aliev ZH (2003) Irrigated agriculture in the mountain and foothill regions of Azerbaijan. Monograph Publishing House "Nurlan Zia EPG Ltd" Baku pp. 330.

3. Aliev BH, Aliev ZH (1999) Techniques and technology few intensive irrigations in condition of the mountain region Azerbaijan. "Elm", Baku pp. 220.

4. Aliev ZH (2007) The premises about the most important problem of the agriculture in the provision of water resources mountain and foothill regions Azerbaijan. J. AAS, \# 1-3, Baku, pp. 179-182.

5. Aliev ZH (1999) In the mountains and foothill region of Azerbaijan. The works SRI “Erosions and Irrigations”, Baku, pp. 125-129

6. Guseynov NM (1969) Ways to improve the efficiency of irrigation, improved technologies and methods for irrigation of agricultural crops in Azerbaijan. Report on the degree of competition CCD on the basis of works, Baku, pp. 214-230.

7. (2002) Mezhdunarodny Center C / X Research in the Dry in the Dry Areas (ICARDA) Irrigation regime and monitoring equipment. U Umarova and A Karimov, Taraz: IC “AQUA”, pp. 128.

8. VF Nosenko (1981) Irrigation in the mountains. Publishing House "Kolos" Moscow, pp. 143.

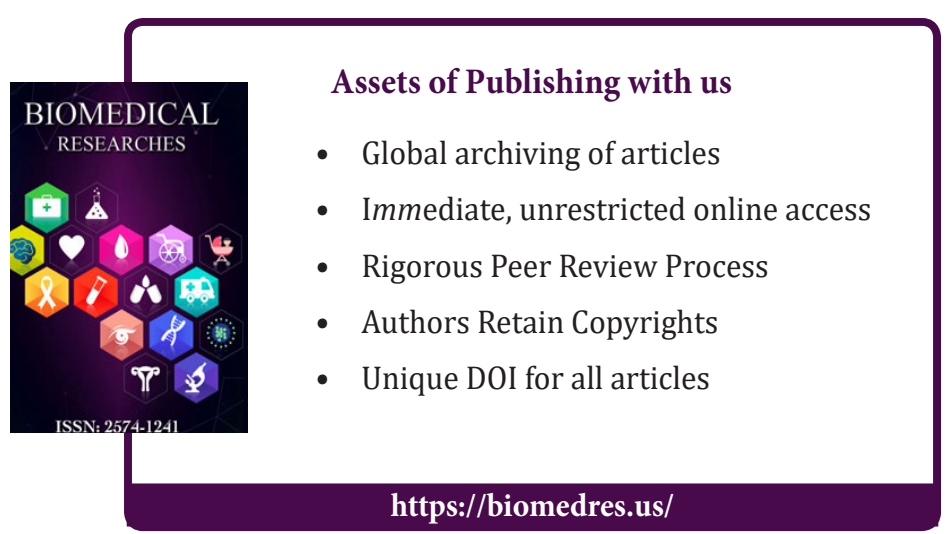

